\title{
Factors that influenced access and utilisation of sexual and reproductive health services among Ugandan youths during the COVID-19 pandemic lockdown: An online cross-sectional survey
}

\section{Simon Binezero Mambo}

Kampala International University - Western Campus

Franck K. Sikakulya ( $\nabla$ francksikakulya@gmail.com )

Kampala International University - Western Campus https://orcid.org/0000-0001-8101-273X

Robinson Ssebuufu

Kampala International University - Western Campus

Yusuf Mulumba

Mulago National Referral Hospital

\section{Henry Wasswa}

Reproductive Health Uganda

Kelly Thompson

Reproductive Health and Right USA

Jean Christophe Rusatira

Bill \& Melinda Gates Institute for Population and Reproductive Health

Fiona Bhondoekhan

Hopkins Bloomberg School of Public Health

Louis K. Kamyuka

Kampala International University - Western Campus

\section{Surat Olabisi Akib}

Kampala International University - Western Campus

Claude Kirimuhuzya

Kampala International University - Western Campus

Jane Nakawesi

Mildmay Uganda

\section{Patrick Kyamanywa}

Kampala International University - Western Campus

\section{Research}

Keywords: Sexual reproductive health, COVID-19, lockdown, youth, Uganda 
Posted Date: January 25th, 2021

DOI: https://doi.org/10.21203/rs.3.rs-48529/v4

License: (c) (1) This work is licensed under a Creative Commons Attribution 4.0 International License. Read Full License 


\section{Abstract}

Background The COVID-19 pandemic has disrupted health care access in many countries. The aim of this study was to explore factors that influenced access and utilisation of sexual and reproductive health services among Ugandan youths during the COVID-19 pandemic lockdown.

Methods This was across-sectional study carried out from April 2020 to May 2020 in Uganda. A questionnaire was administered online to participants aged 18 to 30 years. Subjects were recruited using a snowballing approach. STATA version 14.2 was used for statistical analysis.

Results Of 724 participants, 203 (28\%) reported that they did not have access to information and/or education concerning sexual and reproductive health $(\mathrm{SRH})$. More than a quarter of the participants $(26.9 \%$, $\mathrm{n}=195$ ) reported that testing and treatment services of sexually transmitted infections were not available during the lockdown. $27.2 \%$ could not obtain contraceptive supplies. Access to HIV services and menstrual supplies were also impaired. Lack of transportation was the commonest factor cited as limiting access to $\mathrm{SRH}$ services during the lockdown (68.7\%), followed by the long distance from home to SRH facilities (55.2\%), high cost of services (42.2\%) and the curfew (39.1\%). Sexually transmitted infections were the commonest SRH problems related to SRH during the lockdown (40.4\%) followed by unwanted pregnancy (32.4\%) and sexual abuse (32.4\%). Marital, educational, and employment status were significantly correlated with the reported experiences of the participants.

Conclusion Access to SRH information and services for Ugandan youths was restricted during the COVID-19 lockdown and may have increased the incidence of poor SRH outcomes. Lack of transportation, distance to health facilities, and high cost of services were important limiting factors. The Government and other stakeholders should incorporate SRH among the priority services to be preserved during future outbreaks.

\section{Plain English Summary}

The global COVID-19 pandemic is disrupting access to healthcare around the world, including sexual and reproductive health (SHR) services. An online cross-sectional study was conducted from April 2020 to May 2020 to explore factors affecting access to SRH services among Ugandan youths during the COVID-19 pandemic lockdown. Seven hundred twenty-four Ugandan youths participated in an online survey. More than a quarter of respondents reported that during the lockdown, they had limited access to SRH information and services, such as testing and treatment for Sexually transmitted infections (STIS), HIV treatment, and contraceptive supplies and services. 8 of the 44 women who were pregnant could not receive prenatal or obstetrical care. Lack of transportation, distance to health facilities, and the high cost of services were the most commonly reported obstacles to access. Marital and employment status as well as education level correlated statistically with reported difficulty accessing SRH information and services. The most commonly reported SRH problems were STI's, followed by unwanted pregnancies, sexual abuse, unsafe abortions, pregnancy complications and lack of antiretroviral drugs. A quarter of the participants reported that they could not get testing and treatment for STI's during the lockdown. $60 \%$ of those using family planning had difficulty acquiring condoms, emergency pills, intrauterine devices and injectables contraceptives. Access to $\mathrm{SRH}$ services could have prevented many of these poor outcomes. These findings indicate that effective 
measures should be put in place to ensure access and availability of sexual and reproductive health services for Ugandan youths during outbreaks such as the COVID-19 lockdown.

\section{Introduction}

On $11^{\text {th }}$ March, 2020, the World Health Organization (WHO) declared COVID-19 to be a pandemic [1]. As of January $10,2021,88,387,352$ cases of COVID-19 had been confirmed worldwide with 1,919,204 deaths. That report included 2,135,878 cases and 47,905 deaths in Africa. By that date, Uganda had registered 37,554 confirmed cases of COVID-19 with 301 reported deaths [2]. Case fatality ratio was $2.2 \%$ globally and $2.2 \%$ in Africa. The numbers of cases and deaths continue to rise rapidly [2-3].

Many governments responded to the pandemic by instituting mass quarantine, lockdown and/or social distancing [4]. Uganda announced a lockdown with dawn to dusk curfew on March 20, 2020, which has severely curtailed access to sexual and reproductive health services, with particular consequences for the young people [5]. Experience in the past epidemics has shown that restricted access to essential health services can result in more deaths than the epidemic itself [6].

During the Ebola outbreaks, governments focused on containing that disease. This included diverting resources away from other health priorities, such as sexual and reproductive health (SRH) [7]. As quarantines and school closures were put in place to contain the spread of disease in many countries across the world $[1,5,8]$, women and adolescent girls became more vulnerable to sexual and reproductive health problems such as coercion, exploitation, sexual abuse, and restricted access to contraception. There were delays in the care of pregnant women and an increase in the number of unsafe abortions [9-10]. In the absence of government focus on sexual and reproductive health, the COVID-19 pandemic should be expected to have a similar impact [7-9]. The United Nations Population Fund (UNFPA) in its COVID-19 Pandemic Global Response Plan emphasized that sexual and reproductive health is a significant public health issue that demands urgent and sustained attention and investment [10]. The Inter-Agency Working Group (IAWG) on reproductive health has also recommended that comprehensive sexual and reproductive health services should be maintained as long as the system is not overstretched with COVID-19 case management [11]

The Government of Uganda issued directives to protect pregnant women's access to maternity services [12]. However, sexual and reproductive health information, were not a priority during the lockdown, resulting in diminished access to contraceptive and menstrual health supplies, and a reduction in SRH programs for comprehensive sex education, reduction of gender-based violence and support for victims of assault [12]. Fear of contracting COVID-19 inhibits both health care providers who provide and people who seek SRH services [13]. The transfer of already limited resources to deal with the pandemic and the absence of health care workers from their original duties limits the capacity to provide other essential SRH services, leading to adverse outcomes of chronic health conditions, disabilities, HIV, and pregnancy [14-15]. Reports are emerging of a rise in gender-based violence, unwanted pregnancy among young girls, unsafe abortion, closure of antenatal care services in some of the public health facilities, and a sharp decline in women and girls seeking SRH services [12]. Youth-friendly corners at health facilities that had been established by the Ministry of 
Health of Uganda and donors to make SRH services more accessible were not available during the lockdown [12].

Even before the COVID19 pandemic, SRH services in Uganda were inadequate [16]. The Uganda demographic health survey of 2016 points to over $25 \%$ teenage pregnancies among sexually active young people by the age of 16 years, and the unmet family planning need in the country stood at $28 \%$ [17-18]. Unintended pregnancy is common in Uganda with the attendant high levels of unplanned births, unsafe abortions, and maternal injury and death [17-18].

This study was carried out to explore factors that influenced access and utilisation of sexual and reproductive health services among Ugandan youths during the COVID-19 pandemic lockdown and to inform appropriate intervention measures to respond to young people's sexual and reproductive health during the health emergencies.

\section{Methods}

\section{Study design and setting}

A nationwide cross-sectional online survey was conducted among the young adults in Uganda during the months of April and May, 2020.

\section{Study Population}

The Uganda youth policy defines youths as all young persons, aged 12 to 30 years [19]. This study was focused on Ugandan youths of consent age of 18 years and above at the time of the study. This age group includes more than 10 million people, $22.9 \%$ of the Ugandan population [20]. As the study was conducted online, participation in the study required internet access, minimal computer literacy level, and ability to operate WhatsApp, Twitter or Facebook.

\section{Data Collection and Instrument}

\section{Data Processing and analysis plan}

The questionnaire was pretested and reviewed to ensure correctness and appropriateness to the local context. STATA version 14.2 was used for statistical analysis (StataCorp, College Station, Texas, USA). Categorical variables were presented using frequencies, graphs and/or figures whereas continuous variables were presented using means, standard deviations (SD).

Bivariate and Multivariate regression analyses were used to investigate correlation of social demographics with factors that impaired access to SRH as well as the experience of problems in sexual and reproductive health during the COVID-19 lockdown with socio-demographics. Results are presented as Crude Prevalence Ratios (CPR) and Adjusted Prevalence Ratios (APR) respectively.

\section{Ethical Considerations}


This study was approved by Kampala International University Research and Ethics Committee (KIU-REC023/202018). Data was collected online. Completion of a consent form was required for participation in the study. Participation in the study was anonymous.

\section{Results}

A total of seven hundred thirty-three (733) participants completed the online questionnaire. Nine (9) participants were excluded from the survey because they were above 30 years of age, thus seven hundred twenty-four (724) were in the analysis.

\section{Socio-demographic characteristics of participants (Table 1)}

$56.4 \%$ were male. $78.0 \%$ were single. Mean age was of $24.4(\mathrm{SD} \pm 2.8)$ years. The majority $(87.2 \%)$ had attained an educational level of university and $27.2 \%$ were salaried employees. Most participants were from central Uganda (37.8\%) followed by western Ugandan (35.1\%). Most were students (46.5\%) at the time of study. $27.2 \%$ were paid employees.

Table 1: Socio-demographic characteristics of participants during the COVID-19 lockdown

\begin{tabular}{ll}
\hline Variable & Frequency N (\%) \\
\hline Sample size & $724(100)$ \\
\hline Sex & $316(43.6)$ \\
\hline Female & $408(56.4)$ \\
\hline Male & $395(54.6)$ \\
\hline Age group in years & $329(45.4)$ \\
\hline 18 to 24 & \\
\hline 25 to 30 & $555(78.0)$ \\
\hline Marital status & $81(11.2)$ \\
\hline Living single & $78(10.8)$ \\
\hline Married & \\
\hline Cohabiting & $631(87.1)$ \\
\hline Education level & $46(6.4)$ \\
\hline University & $47(6.5)$ \\
\hline Vocational or Technical Institution & $274(37.8)$ \\
\hline Secondary School and below & $254(35.1)$ \\
\hline Location/Region in Uganda & $122(16.9)$ \\
\hline Central Uganda & $74(10.2)$ \\
\hline Western Uganda & \\
\hline Eastern Uganda & $337(46.5)$ \\
\hline Northern Uganda & $197(27.2)$ \\
\hline Employment status & $62(8.6)$ \\
\hline Students & $69(9.5)$ \\
\hline Paid employment (employee on a salary) & $59(8.1)$ \\
\hline Self-employed (Business/Income Generating Activity &
\end{tabular}


Table 2 shows the reported availability of SRH services to the participants in this study. Out of 724 participants, $203(28.0 \%)$ reported no access to information on or education in sexual health. Regarding STI's, one hundred ninety-five participants $(26.9 \%)$ reported that they did not have access to testing and treatment for STIs. $29.6 \%$ participants did not know whether such services and information were available. $27.2 \%$ of participants did not have easy access to their preferred modern method of contraception during the COVID-19 lockdown. $22 \%$ of participants reported that they had needed HIV testing and counselling but could not obtain those services. 50 of the 62 participants who were on HIV treatment had difficulty in getting HIV drugs during the lockdown. $40 \%$ of the women who needed menstrual health products had difficulty obtaining these supplies. 8 of the 44 participants who were pregnant at the time of the study could not get maternity care. 5 of the 24 participants who had an abortion during the study could not get follow up care after the procedure.

Table 2. Access to sexual and reproductive health services among Ugandan youths during the COVID-19 lockdown

\begin{tabular}{lc}
\hline Variables & $\begin{array}{c}\text { All (\%) } \\
\text { n=724 }\end{array}$ \\
\hline Availability of information and/or education concerning sexuality & $203(28.0 \%)$ \\
No & $521(72.0 \%)$ \\
Yes & $195(26.9 \%)$ \\
Availability of testing and treatment services of STIs & $315(43.5 \%)$ \\
No & $214(29.6 \%)$ \\
Yes & \\
Don't know & $197(27.2 \%)$ \\
Access to the preferred modern contraceptive & $132(18.2 \%)$ \\
Not Easily & $395(54.6 \%)$ \\
Easily & $159(22 \%)$ \\
Not Applicable & $349(48.2 \%)$ \\
Availability of HIV testing and counselling services & $216(29.8 \%)$ \\
No & \\
Yes & $50(6.9 \%)$ \\
I Don't know & $12(1.7 \%)$ \\
Access to Antiretroviral therapy (medication) & $662(91.4 \%)$ \\
Easily & \\
Not Applicable & $127(17.5 \%)$ \\
Access to menstrual health products such as sanitary pads & $189(26.1 \%)$ \\
Not Easily & $408(56.4 \%)$ \\
Easily & $36(81.8 \%)$ \\
Not Applicable & $8(18.2 \%)$ \\
Yvailability of pregnancy care & \\
No & $19(79.2 \%)$ \\
Access to post abortion care services & $5(20.8 \%)$ \\
Yes &
\end{tabular}

Nearly half of the participants ( $n=357 ; 49.3 \%$ ) reported using family planning methods, the overwhelming majority of which used modern methods (Figure 1). Of the 320 participants using modern contraception, the 
majority ( $n=232 ; 72.5 \%)$ used condoms. 33 reported using emergency pills, 22 relied on an IUD. 33 on an injectable contraceptive, and 13 used implants.

Lack of transport was the most commonly reported factor that impaired access to SRH services (43\%), followed by distance from home (34.5\%), cost of services $(26.4 \%)$ and curfew $(24.4 \%)$. Other factors were fear or/negative provider attitude (22.5\%), no service provider (21.3\%), school closure $(12.3 \%)$ and lack of knowledge as to where SRH services could be obtained (Figure 2).

The Ugandan youths ( $\mathrm{n}=136$ or $18.8 \%$ ) reported having SRH problems during the lockdown. STIs $(40.4 \%)$ were the commonest problem, followed by unwanted pregnancy (32.4\%) and sexual abuse (32.4\%). Other $\mathrm{SRH}$ problems included unsafe abortions, pregnancy complications, lack of anti-retroviral drugs (ARVs), death of a child and obstetrical fistula (Figure 3).

\section{Influence of socio-demographic status}

Bivariate analysis found a statistically significant correlation between marital status and reports of difficulty in accessing SRH information and treatment $(p<0.001$, Table 3$)$. Cohabiting people were more likely to report problems than married people, while single people were least likely. Both bivariate and multivariate analyses indicated statistically significant correlations of educational status with reports of poor access to SRH information and services $(p<0.001)$. People with university education were less likely to report encountering problems. No statistically significant influence was found for either geographic location or employment status, although there was a trend for.

Table 3: Bivariate and Multivariate regression analyses using Poisson Regression of having a limiting factor to access SRH among Ugandan youths with their social demographics during the COVID-19 lockdown 


\begin{tabular}{|c|c|c|c|c|}
\hline Variable & CPR (95\%CI) & P-Value & APR $(95 \% \mathrm{CI})$ & P-Value \\
\hline Sex & & 0.965 & & 0.997 \\
\hline Female & 1 & & 1 & \\
\hline Male & $1(0.89-1.12)$ & & $1(0.89-1.12)$ & \\
\hline Age group in years & & 0.740 & & 0.424 \\
\hline 18 to 24 & 1 & & 1 & \\
\hline 25 to 30 & $1(0.91-1.14)$ & & $0.9(0.83-1.08)$ & \\
\hline Marital status & & $<0.001$ & & 0.016 \\
\hline Single & 1 & & 1 & \\
\hline Married & $1.2(1.04-1.41)$ & & $1.1(0.97-1.36)$ & \\
\hline Cohabiting & $1.3(1.13-1.49)$ & & $1.2(1.06-1.41)$ & \\
\hline Education level & & $<0.001$ & & 0.001 \\
\hline University & 1 & & 1 & \\
\hline Vocational or Technical Institution & $1.4(1.27-1.65)$ & & $0.9(0.72-1.08)$ & \\
\hline Secondary School & $1.2(1-1.45)$ & & $1.2(0.94-1.48)$ & \\
\hline Location/Region in Uganda & & 0.088 & & 0.294 \\
\hline Central Uganda & 1 & & 1 & \\
\hline Western Uganda & $1(0.91-1.2)$ & & $1(0.9-1.2)$ & \\
\hline Eastern Uganda & $1.2(1.03-1.4)$ & & $1.2(0.99-1.34)$ & \\
\hline Northern Uganda & $1.1(0.95-1.39)$ & & $1.1(0.92-1.34)$ & \\
\hline Employment status & & 0.048 & & 0.025 \\
\hline Student & 1 & & 1 & \\
\hline Paid employment (employee on a salary) & $1.1(0.94-1.23)$ & & $1(0.87-1.2)$ & \\
\hline Self-employed (Business/Income Generating Activity) & $1.2(1-1.44)$ & & $1.1(0.94-1.41)$ & \\
\hline Unemployed: No structured activity & $1(0.79-1.22)$ & & $1(0.79-1.21)$ & \\
\hline Unemployed: Volunteer/ non-salaried & $1.3(1.09-1.53)$ & & $1.2(1-1.42)$ & \\
\hline
\end{tabular}

APR: Adjusted Prevalence ratio; CI: Confident Interval; CPR: Crude prevalence ratio

\section{Correlation of socio-demographic factors with the reported SRH health problems}

Reported incidence of SRH problems was significantly correlated with marital status ( $p<.001$, Table 4$)$. People who co-habited were most likely to report problems, while single people were least likely. Education level also had a significant influence, as university educated participants were less likely to report SRH problems.

Table 4: Bivariate and Multivariate regression analyses of the correlation demographic factors with reported SRH problems among Ugandan youths during the COVID-19 lockdown 


\begin{tabular}{|c|c|c|c|}
\hline CPR (95\%CI) & P-Value & APR (95\%CI) & P-Value \\
\hline Sex & 0.902 & & 0.994 \\
\hline Female & 1 & 1 & \\
\hline Male & $1(0.72-1.33)$ & $1(0.74-1.35)$ & \\
\hline Age group in years & 0.080 & & 0.661 \\
\hline 18 to 24 & 1 & 1 & \\
\hline 25 to 30 & $1.3(0.97-1.78)$ & $1.1(0.76-1.54)$ & \\
\hline Marital status & $<0.001$ & & $<0.001$ \\
\hline Single & 1 & 1 & \\
\hline Married & $2(1.38-3.02)$ & $1.5(0.99-2.32)$ & \\
\hline Cohabiting & $2.7(1.88-3.74)$ & $2.3(1.60-3.29)$ & \\
\hline Education level & $<0.001$ & & 0.001 \\
\hline University & 1 & 1 & \\
\hline Vocational or Technical Institution & $2.3(1.51-3.47)$ & $0.5(0.31-0.74)$ & \\
\hline Secondary School & $2.2(1.47-3.4)$ & $0.8(0.45-1.33)$ & \\
\hline Location/Region in Uganda & 0.306 & & 0.748 \\
\hline Central Uganda & 1 & 1 & \\
\hline Western Uganda & $1.1(0.74-1.56)$ & $1.1(0.75-1.53)$ & \\
\hline Eastern Uganda & $1.5(0.97-2.2)$ & $1.2(0.82-1.79)$ & \\
\hline Northern Uganda & $1.1(0.66-1.94)$ & $0.9(0.55-1.59)$ & \\
\hline Employment status & 0.034 & & 0.198 \\
\hline Student & 1 & 1 & \\
\hline Paid employment (employee on a salary) & $1.5(1.03-2.12)$ & $1.2(0.76-1.76)$ & \\
\hline Self-employed (Business/Income Generating Activity) & $1.7(1.04-2.79)$ & $1.2(0.73-2.09)$ & \\
\hline Unemployed: No structured activity & $0.7(0.32-1.41)$ & $0.7(0.33-1.44)$ & \\
\hline Unemployed: Volunteer or unpaid work & $2(1.27-3.2)$ & $1.6(1.03-2.64)$ & \\
\hline
\end{tabular}

APR: Adjusted Prevalence ratio; CI: Confident Interval; CPR: Crude prevalence ratio

\section{Discussion}

In response to the COVID-19 Pandemic, Uganda introduced one of the most stringent lockdowns in Africa. The government banned public gatherings, shut down shopping centres, places of worship, schools and entertainment centres, restricted travel, and enacted a night-time curfew [12,23]. Although the travel ban was partially lifted for pregnant women and people with HIV/AIDS, the government did not address access to other essential SRH services such as contraceptives, menstrual sanitary supplies, and access to treatment for HIV $[12,14]$.

Many participants in this study reported poor access to SRH during the lockdown.

Inadequate access was already a significant problem before the pandemic in Uganda as well as in many other developing countries [14,24-25]. A 2015 study reported a significant unmet need for SRH services for young people in Wakiso district in Uganda [24]. A qualitative study in the Kaborole district found widespread 
misinformation about contraception and STIs [26]. Two major surveys in Uganda found that students, including those engaged in high-risk sexual behaviours, had limited access to SRH services and HIV/AIDSrelated programmes [27-28]. Despite efforts to improve access to SRH services, a survey of 70 resource poor countries found that less than $10 \%$ of adolescent women had access to health facilities and information about family planning [25]. Inadequate access to SRH information and services has also been reported by studies in Kenya, Zambia, and Swaziland [29-30].

Global health emergencies dictate shifts in priorities that present problems to the availability, accessibility and affordability of SRH services [14]. During prior outbreaks poor access to SRH resources has been associated with increased maternal and childhood mortality [14]. During West Africa's large, multi-country Ebola Virus Disease (EVD) outbreak of 2014-2016 increased maternal mortality was attributed to closures of health facilities. Additionally, health care staff were reluctant to provide obstetrical care because infection control measures were inadequate, and they feared for their own safety [31]. A study in Guinea found a decrease of $51 \%$ in Family Planning (FP) visits during an Ebola outbreak [32]. Economic factors seemed to drive a spike in pregnancy occurred during an Ebola outbreak in Liberia. Girls reportedly had sex in exchange for water, food, or other forms of financial protection [33].

This study documented restricted access to family planning in Uganda during the COVID-19 lockdown. Nearly half of the participants reported the use of contraception. But among those who used modern contraception, $59 \%$ had difficulty accessing their preferred method.

Lack of transport was the commonest (68.7\%) limiting factor to accessing SRH services and information during the lockdown. This was followed by physical distance from home to the health care facility ( $55.2 \%)$, cost of services (42.2\%) and curfew (39.1\%). Travel in motor vehicles, including private cars, taxis and buses, was banned in an effort to contain the spread of the COVID-19 in the community. Lack of motor transportation is compounded if the clinic is so far from home that walking is impractical. The lockdown also had an economic impact, as businesses closed, unemployment increased, and the cost of living increased. Thus, SRH services became less affordable. Inequalities in the disease burden and access to health care is prominent concern in Uganda and the economic impact of the shutdown could only exacerbate this problem [34].

STIs were the most commonly reported SRH problem. Lack of access to treatment is not only a problem for the infected individual. It is a public health problem due to potential spread of the disease. Participants also reported unwanted pregnancies, a significant public health problem that existed long before the pandemic. In 2008, more than half of the 2.2 million pregnancies in Uganda were unwanted [35]. Teenage pregnancy has increased in Uganda during the COVID-19 lockdown [36]. The closing of schools may have played a role in this increase as girls are more vulnerable to abuse or rape without access to this secure environment. But it is logical that a major factor was lack of access to SRH services, which are critical in the prevention of unwanted pregnancies, unsafe abortion, reducing maternal and child morbidity and mortality as well as reducing poverty and empowering women [37]. Additionally, in a poor economy, girls may resort to sex for money. 
This study had some limitations. In-depth interviews and focus group discussions to enrich the study findings were not possible, due to social distancing restrictions during the pandemic. The study was limited to the youths who had access to internet and social media and an understanding of the English language. Furthermore, a respondent driven virtual snowball sampling method was used so our findings may not be taken as a representation for the general Ugandan youths' population. Our sample was skewed, as a very high percentage of participants had a university education. Finally, we do not have baseline comparison data from before the COVID-19 lockdown.

\section{Conclusion}

In this study, Ugandan youths reported poor access to sexual and reproductive health services during the COVID-19 lockdown. Lack of transportation and the price of services were the commonest factors reported as limiting access to SRH services. STIs and unwanted pregnancies were the most prevalent problems faced by Ugandan youths during the COVID-19 lockdown. We hope these findings will inform policymakers about the need to ensure access to care and information in regards to SRH for Ugandan youths, particularly for women and the poor.

There is a need for the Uganda government to collaborate with other stakeholders in developing guidelines for ensuring access to SRH information and services during any future outbreaks. Such guidance should include response plans for health facilities and the communities.

New public health approaches are needed to strengthen supply chains and public information during crises that disrupt schools, health services, and community centres. Policymakers should define and promote sexual and reproductive health care as an essential service during any outbreak.

\section{List Of Abbreviations}

APR: Adjusted Prevalence Ratio

Cl: Confident Interval

COVID-19: Coronavirus Disease 2019

CSG: Coronavirus Study Group

DRC: Democratic Republique of the Congo

HIV: Human Immunodeficiency Virus

$\mathrm{MOH}$ : Ministry of Health

SARs: Severe Acute Respiratory Syndrome Coronavirus 2

SRH: Sexual and Reproductive Health

UBOS: Uganda Bureau of Statistics 


\section{Declarations}

\section{Ethical approval and consent to participate}

Expedited ethical approval was acquired from Kampala International University Research and Ethics Committee (KIU-REC-023/202018). Consent to participate was obtained through online acceptance.

\section{Consent for publication}

Not applicable

\section{Competing interest}

Authors declare no competing interest.

\section{Authors contributions}

SBM and RS were the principal investigators, conceived and designed the survey, supervised the online data collection and critically reviewed the manuscript. YM analysed data; FKS, KT, SOA and JN reviewed the manuscript development and revised the data tool. JCR and FB revised the methodology. HW and LKK participated in online data collection; FKS, CK and PK critically reviewed the manuscript. All authors read and approved the final manuscript.

\section{Acknowledgement}

Authors are grateful to Prof. Gayle Woodson for proofreading this manuscript.

\section{Funding}

Not applicable

\section{References}

1. COVID-19: situation update for WHO African Region. World Heal Organ [Internet]. 2020;1-5. Available from: https://apps.who.int/iris/bitstream/handle/10665/331840/SITREP_COVID19_WHOAFRO_20200422-eng.pdf (accessed January 11, 2021).

2. World Health Organisation Coronavirus disease 2019 (COVID-19) Situation Report. Geneva: WHO; (2020). Available online at: who.int/emergencies/diseases/novel-coronavirus-2019/situationreports(accessed January 11, 2021).

3. World Health Organisation Coronavirus Disease (COVID-19) Dashboard: WHO. Available from: https://covid19.who.int/table (accessed January 11, 2021).

4. Brooks SK, Webster RK, Smith LE, Woodland L, Wessely S, Greenberg N, et al. The psychological impact of quarantine and how to reduce it: rapid review of the evidence. Lancet [Internet]. 
2020;395(10227):912-20. Available from: http://dx.doi.org/10.1016/S0140-6736(20)30460-8 (accessed September 20, 2020).

5. Rica C. Contributing to Rights and Choices. 2019. UNFPA Government Core Contributors in 2019. Available from: https://www.unfpa.org/sites/default/files/resource-pdf/20-019UNFPA-CoreResrcBro-v32020-02-01-1022-PRESS.pdf (accessed September 20, 2020).

6. McQuilkin PA, Udhayashankar K, Niescierenko M, Maranda L. Health-care access during the Ebola virus epidemic in Liberia. Am J Trop Med Hyg. 2017;97(3):931-6.

7. McKay G, Black B, Mbambu Kahamba S, Wheeler E, Mearns S, Janvrin A. Not all that Bleeds is Ebola: How has the DRC Ebola outbreak impacted Sexual and Reproductive Health in North-Kivu? New York, USA: The International Rescue Committee 2019. Available from:

https://reliefweb.int/sites/reliefweb.int/files/resources/srhebolareport1172020.pdf (accessed September 13, 2020).

8. Society, A. C., \& To, C. (2020). Mitigating covid-19 impacts on sexual and reproductive health and rights in low- and middle-income countries. Available from: https://pai.org/wpcontent/uploads/2020/04/SRHR-and-COVID-4.17.pdf (accessed September 12, 2020).

9. Riley, T., Sully, E., Ahmed, Z., \& Biddlecom, A. (2020). Estimates of the potential impact of the covid-19 pandemic on sexual and reproductive health in low-and middle-income countries. International Perspectives on Sexual and Reproductive Health, 46, 73-76. Available from: https://doi.org/10.1363/46e9020 (accessed September 02, 2020).

10. Secretary-general, U. N. (2020). Coronavirus Disease ( COVID-19) Pandemic UNFPA Global Response Plan. April. Available from: https://www.unfpa.org/sites/default/files/resourcepdf/UNFPA_Global_Response_Plan_Revised_June_2020_.pdf (accessed September 25, 2020).

11. Programmatic Guidance for Sexual and Reproductive Health in Humanitarian and Fragile Covid-19 Pandemic. 2020;(April):2017-20. Available from: https://cdn.iawg.rygn.io/documents/IAWG-FullProgrammatic-Guidelines.pdf?mtime=20200505142838\&focal=none (accessed July 20, 2020).

12. Daily Monitor. How Covid-19 is affecting reproductive health efforts. [Online].; 2020a. Available from: https://www.monitor.co.ug/Magazines/Full-Woman/How-Covid19-is-affecting-reproductivehealth/689842-5533118-umkxsoz/index.html (accessed April 20, 2020).

13. Note, I. T. (2020). Impact of the COVID-19 Pandemic on Family Planning and Ending Gender-based Violence, Female Genital Mutilation and Child Marriage. April, 1-7. Available from: https://www.unfpa.org/sites/default/files/resource-pdf/COVID19_impact_brief_for_UNFPA_24_April_2020_1.pdf (accessed April 20, 2020).

14. Chattu VK, Yaya S. Emerging infectious diseases and outbreaks: Implications for women's reproductive health and rights in resource-poor settings. Reprod Health. 2020;17(1):1-5.

15. To B, Crisis THE, Regions INALL, Continue W, Get TO, Babies H, et al. Impact on srhr in humanitarian crises - Summer 2014. 2014;(11):1-11.

16. Nsubuga H, Sekandi JN, Sempeera H, Makumbi FE. Contraceptive use, knowledge, attitude, perceptions and sexual behavior among female University students in Uganda: A cross-sectional survey. BMC 
Womens Health [Internet]. 2016;16(1):1-11. Available from: http://dx.doi.org/10.1186/s12905-0160286-6 (accessed April 29, 2020).

17. Statistics UB of. Uganda Demographic and Health Survey 2016. Foreign Aff. 2017;(6):1-58.

18. Hussain R, Unintended pregnancy and abortion in Uganda, In Brief, New York: Guttmacher Institute, 2013, No 2. Available from: https://www.guttmacher.org/sites/default/files/pdfs/pubs/IB-UnintendedPregnancy-Uganda.pdf (accessed April 20, 2020).

19. House L, House U. Definition of Youth Factsheet: Uganda. 2016;(October 2014). Available from: https://www.youthpolicy.org/pdfs/factsheets/uganda.pdf (accessed October 20, 2020).

20. Statistical Abstract, 2019. Uganda Bur Stat Stat [Internet]. 2019; Available from: http://www.ubos.org/onlinefiles/uploads/ubos/pdf/documents/abstracts/Statistical/Abstract/2013.pdf (accessed April 20, 2020).

21. Renzaho AMN, Kamara JK, Georgeou N, Kamanga G. Sexual, reproductive health needs, and rights of young people in Slum Areas of Kampala, Uganda: A cross sectional study. PLoS One. 2017;12(1):1-21.

22. Barros AJ, Hirakata VN. Alternatives for logistic regression in cross-sectional studies: an empirical comparison of models that directly estimate the prevalence ratio. BMC Med Res Methodol. 2003 Oct 20;3:21. doi: 10.1186/1471-2288-3-21. PMID: 14567763; PMCID: PMC521200

23. Ssebuufu, R. et al. (2020) 'Knowledge, Attitude, and Self-Reported Practice Toward Measures for Prevention of the Spread of COVID-19 Among Ugandans: A Nationwide Online Cross-Sectional Survey', Frontiers in Public Health /, 8(December), pp. 1-9. doi: 10.1101/2020.05.05.20092247.

24. Atuyambe, L.M., Kibira, S.P.S., Bukenya, J. et al. Understanding sexual and reproductive health needs of adolescents: evidence from a formative evaluation in Wakiso district, Uganda. Reprod Health 12, 35 (2015). https://doi.org/10.1186/s12978-015-0026-7 (accessed April 20, 2020).

25. Woog V, Singh S, Browne A, Philbin J. Adolescent women's need for and use of sexual and reproductive health services in developing countries. New York Guttmacher Inst. 2015;(August):1-63.

26. Kipp W, Chacko S, Laing L, Kabagambe G. Adolescent reproductive health in Uganda: Issues related to access and quality of care. Int J Adolesc Med Health. 2007;19(4):383-93.

27. Renzaho AMN, Kamara JK, Georgeou N, Kamanga G. Sexual, reproductive health needs, and rights of young people in Slum Areas of Kampala, Uganda: A cross sectional study. PLoS One. 2017;12(1).

28. Rutherford GW, Anglemyer A, Bagenda D, Muyonga M, Lindan CP, Barker JL, et al. University students and the risk of HIV and other sexually transmitted infections in Uganda: The crane survey. Int $\mathrm{J}$ Adolesc Med Health. 2014;26(2):209-15.

29. Warenius LU, Faxelid EA, Chishimba PN, Musandu JO, Ong'any AA, Nissen EBM. Nurse-Midwives' Attitudes towards Adolescent Sexual and Reproductive Health Needs in Kenya and Zambia. Reprod Health Matters. 2006;14(27):119-28.

30. Pearson S. Promoting sexual health services to young men: Findings from focus group discussions. $J$ Fam Plan Reprod Heal Care. 2003;29(4):194-8.

31. Figueroa CA, Linhart CL, Beckley W, Pardosi JF. Maternal mortality in Sierra Leone: from civil war to Ebola and the Sustainable Development Goals. Int J Public Health [Internet]. 2018;63(4):431-2. [Available from: https://doi.org/10.1007/s00038-017-1061-7] 
32. Camara BS, Delamou A, Diro E, Béavogui AH, El Ayadi AM, Sidibé S, et al. Effect of the 2014/2015 Ebola outbreak on reproductive health services in a rural district of Guinea: An ecological study. Trans $\mathrm{R}$ Soc Trop Med Hyg. 2017;111(1):22-9.

33. Korkoyah, D. T., \& Wreh, F. F. (2015). Ebola impact revealed: An assessment of the differing impact of the outbreak on the women and men in Liberia. July. Available from: https://www-cdn.oxfam.org/s3fspublic/file_attachments/rr-ebola-impact-women-men-liberia-010715-en.pdf (accessed July 20, 2020).

34. Kiwanuka, S. N., Ekirapa, E. K., Peterson, S., Okui, O., Rahman, M. H., Peters, D., \& Pariyo, G. W. (2008). Access to and utilisation of health services for the poor in Uganda: a systematic review of available evidence. Transactions of the Royal Society of Tropical Medicine and Hygiene, 102(11), 1067-1074.

35. Shaw D. Access to sexual and reproductive health for young people: Bridging the disconnect between rights and reality. Int J Gynecol Obstet. 2009;106(2):132-6.

36. Global G.L.O.W. The Consequences of Covid-19 for Girls in Uganda [Internet]. 2020;1-5. Available from: https://globalgirlsglow.org/the-consequences-of-covid-19-for-girls-in-uganda/ (accessed December 15, 2020).

37. Hubacher D, Mavranezouli I, Mcginn E. Unintended pregnancy in sub-Saharan Africa: magnitude of the problem and potential role of contraceptive implants to alleviate it. 2008;78:73-8.

\section{Figures}

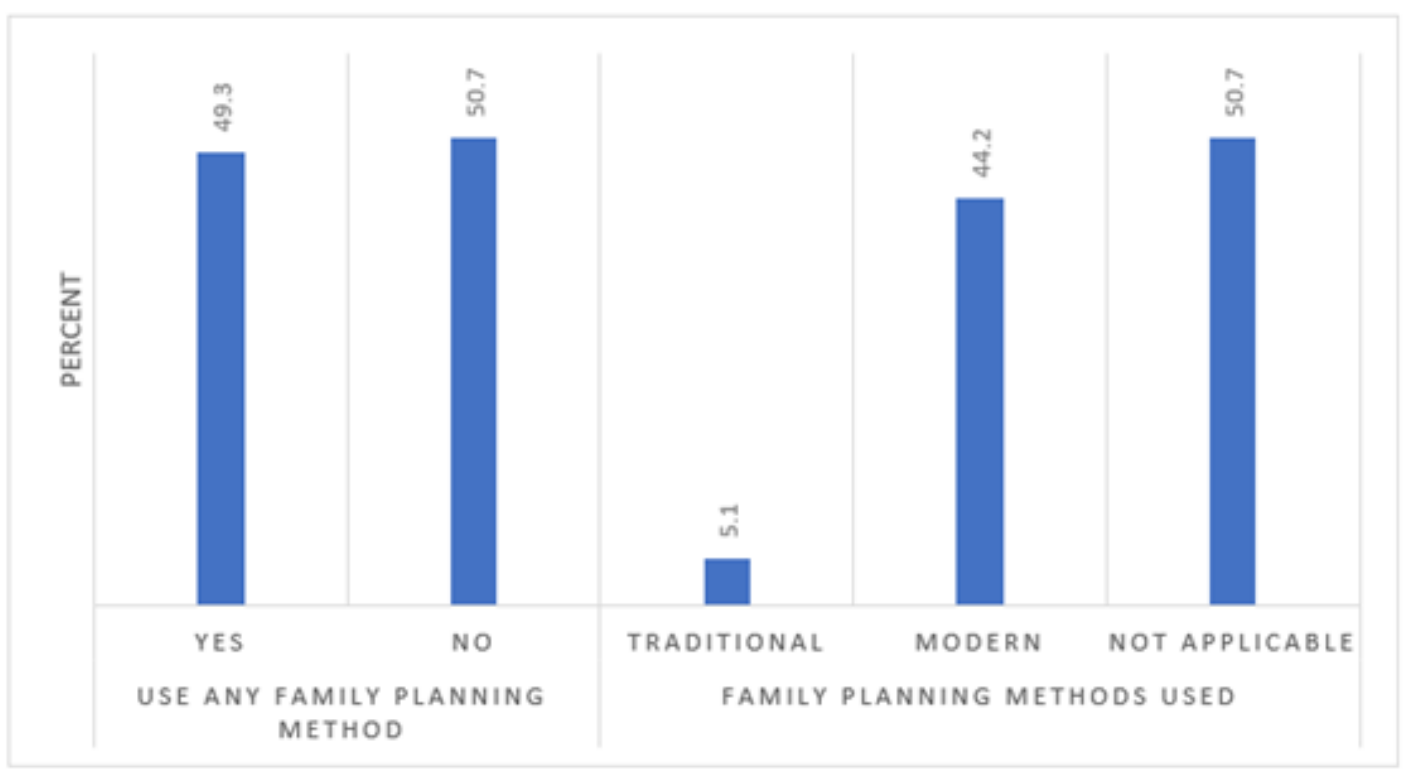

\section{Figure 1}

Methods of family planning used by the Ugandan youths during the COVID-19 lockdown 


\section{Limiting factors to access sexual and reproductive health services and information}

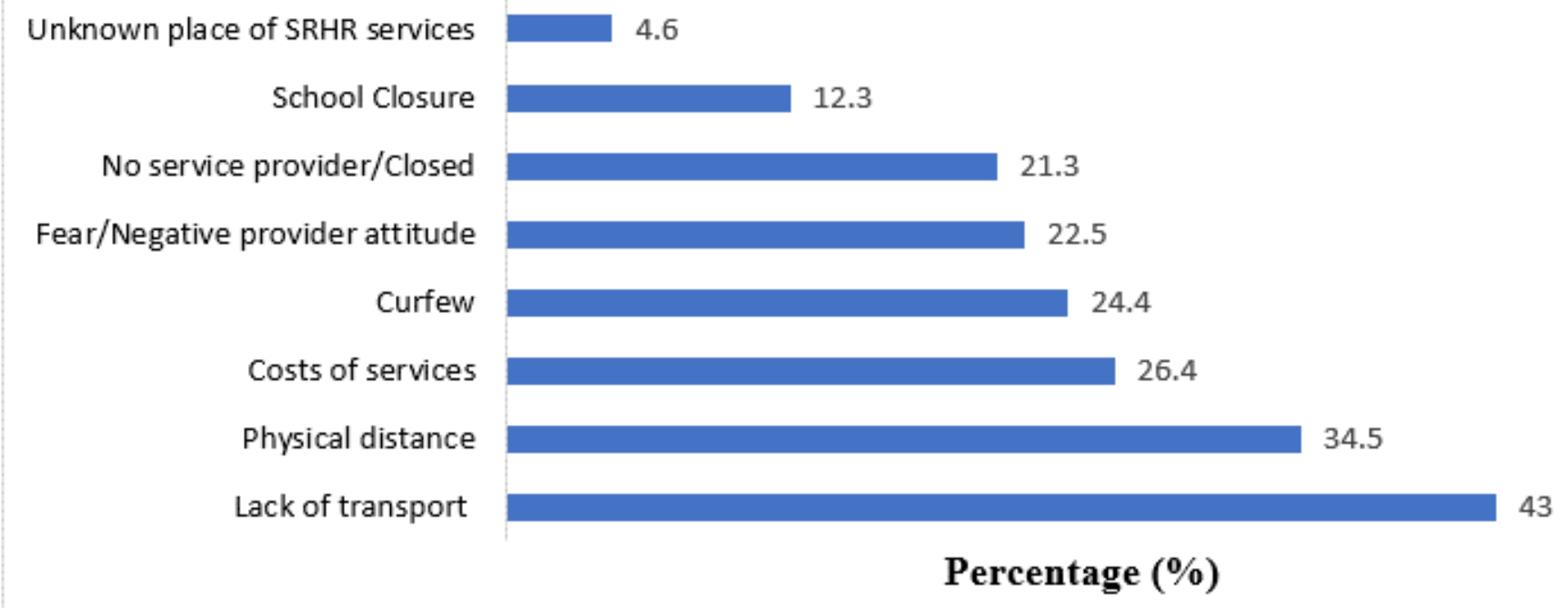

\section{Figure 2}

Limiting factors to access sexual and reproductive health services and information among Ugandan youths during the COVID-19 lockdown

\section{Problems related to sexual and reproductive health}

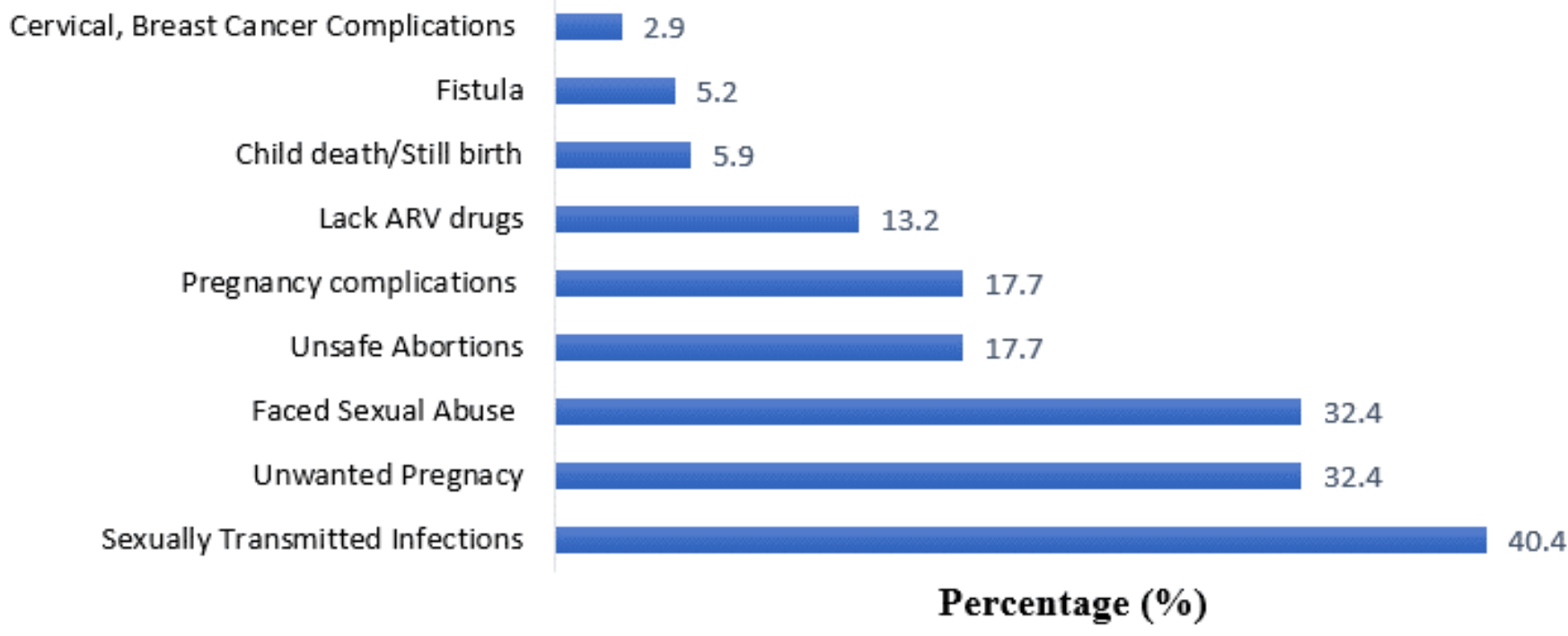

Figure 3

Problems relating to sexual and reproductive health and rights among Ugandan youths during the COVID-19 lockdown 


\section{Supplementary Files}

This is a list of supplementary files associated with this preprint. Click to download.

- S1Table.docx 